\title{
Effects of Punica granatum Flowers on Carbohydrate Metabolizing Enzymes, Lipid Peroxidation and Antioxidants Status in Streptozotocin Induced Diabetic Rats
}

\author{
S. Manoharan ${ }^{1, *}$, R. Anish $\operatorname{Kumar}^{1}$, A. Linsa Mary ${ }^{1}$, R.B. Singh ${ }^{2}$, S. Balakrishnan ${ }^{1}$ and S. Silvan ${ }^{1}$ \\ ${ }^{I}$ Department of Biochemistry and Biotechnology, Faculty of Science, Annamalai University, Annamalainagar-608002, \\ Tamil Nadu, India \\ ${ }^{2}$ Halberg Hospital and Research Institute, Civil Lines, Moradabad-10, Uttar Pradesh, India
}

\begin{abstract}
The mechanistic pathway for the antidiabetic efficacy of ethanolic extract of Punica granatum flowers (PgEFet) has been investigated by measuring the status of blood glucose, plasma insulin, carbohydrate metabolizing enzymes, lipid peroxidation and antioxidants as biochemical end points in streptozotocin induced diabetic rats. Diabetes mellitus was induced by single intraperitoneal injection of streptozotocin $(50 \mathrm{mg} / \mathrm{kg} \mathrm{b.w})$ in albino Wistar rats. Oral administration of PgEFet (400mg/kg b.w) by gastric gavage to diabetic animals significantly reduced the level of blood glucose and increased the level of plasma insulin as well as reverted the disturbed activities of carbohydrate metabolizing enzymes to near normal pattern. Also, PgEFet exhibited potent anti-lipid peroxidative and antioxidant function in streptozotocin induced diabetic rats. The present study thus concludes that the antidiabetic efficacy of Punica granatum flowers in streptozotocin induced diabetic rats relies on its modulating effect on carbohydrate metabolizing enzymes as well as its anti-lipid peroxidative and antioxidant potential.
\end{abstract}

Key Words: Diabetes mellitus, streptozotocin, lipid peroxidation, antioxidants, carbohydrate metabolizing enzymes, Punica granatum.

\section{INTRODUCTION}

Diabetes mellitus, a life threatening as well as life style modifying metabolic disorder, is manifested mainly by hyperglycemia, which results due to defect in insulin secretion, function and or both. Hyperglycemia leads to several acute and long-term complications if it persists for longer time. Diabetes mellitus exhibits wide geographic variation in its incidence and prevalence. According to the World Health Organization, approximately 171 million people worldwide are affected by diabetes mellitus. It has been assumed that 57.2 million Indian will be affected by diabetes mellitus by the year 2025, mainly due to a vast growth in population $[1,2]$.

Streptozotocin induced experimental diabetes mellitus is an ideal model to study the antidiabetic activity of medicinal plants and its constituents. Streptozotocin induces diabetes mellitus by destroying pancreatic $\beta$ cells, possibly through generating excess reactive oxygen species (ROS). Streptozotocin generated lipid peroxidation and DNA breaks in pancreatic islets cells have been demonstrated [3]. Oxidative stress, an imbalance in oxidant and antioxidant status, has been implicated in the pathogenesis of diabetes mellitus and its complications. Oxygen free radicals are formed disproportionately in diabetic condition due to glucose auto-oxidation, non-enzymatic glycation of proteins and

*Address correspondence to this author at the Department of Biochemistry $\&$ Biotechnology, Faculty of Science, Annamalai University, Annamalainagar-608002, Tamil Nadu, India; Tel: + 91- 4144-238343; Fax: + 91- 4144238080; E-mail: sakshiman@ rediffmail.com subsequent oxidative degration of glycated proteins [4]. Over production of ROS and insufficient antioxidant defense mechanism were well documented in diabetic patients as well as in experimental diabetes mellitus [5, 6].

Punica granatum (Pomegranate), a fruit-bearing deciduous shrub or small tree, is native to the region from Afghanistan, Pakistan, and Iran to the Himalayas in northern India and has been cultivated and naturalized over the whole Mediterranean region since ancient times. Diverse pharmacological and therapeutic effects of Punica granatum were reported [7, 8]. The anti-hyperglycemic effect of Punica granatum flowers has been demonstrated in alloxan-induced diabetic rats [9]. Previous study from our laboratory demonstrated the antidiabetic and antihyperlipidemic effects of Punica granatum flowers in streptozotocin induced diabetic rats [10]. However, the mechanistic pathway for its antidiabetic efficacy has not been fully elucidated in streptozotocin induced diabetes mellitus. The present study is thus designed to investigate the antidiabetic efficacy of Punica granatum flowers and its modifying effect on carbohydrate metabolizing enzyme activities, lipid peroxidation and antioxidant status in streptozotocin induced diabetic rats.

\section{MATERIALS AND METHODS}

\section{Animals}

Albino Wistar male rats (8-9 weeks old, weighing 150$200 \mathrm{~g}$ ) were obtained from Central Animal House, Rajah Muthiah Institute of Health Science, Annamalai University, Annamalainagar, India. The rats were housed four or five in polypropylene cages and provided standard pellet diet and 
water ad libitum and maintained under controlled conditions of temperature and humidity, with a $12 \mathrm{~h}$ light/dark cycle in Central Animal House. The animals were maintained as per the principles and guidelines of the ethical committee for animal care of Annamalai University in accordance with the Indian National Law on animal care and use.

\section{Plant Materials}

Flowers of Punica granatum were collected in and around Chidambaram, India and identified by the Botanist Dr. S. Sivakumar, Reader, Department of Botany, Annamalai University. A voucher specimen was also deposited in the Department of Botany, Annamalai University, Annamalainagar, Tamilnadu, India.

\section{Preparation of Ethanolic Extract of Punica Granatum Flowers (PgEFet)}

$500 \mathrm{~g}$ of fresh flowers of Punica granatum were dried in the shade, powdered and then soaked in $1500 \mathrm{ml}$ of $95 \%$ ethanol overnight. After filtration, the residue obtained was again resuspended in equal volume of $95 \%$ ethanol for $48 \mathrm{~h}$ and filtered again. The above two filtrates were mixed and the solvents were evaporated in a rotavapour at $40-50^{\circ} \mathrm{C}$ under reduced pressure. A semisolid dark brown material $(10 \%)$ of Punica granatum flowers obtained was stored at $0-4^{\circ} \mathrm{C}$ until used. A known amount of the residual extract was suspended in distilled water and was orally administered to the animals by gastric gavage during the experimental period.

\section{Induction of Diabetes Mellitus}

Diabetes mellitus was induced in overnight-fast albino Wistar rats by single intraperitoneal injection of streptozotocin $(50 \mathrm{mg} / \mathrm{kg}$ b.w. ip) dissolved in freshly prepared $0.1 \mathrm{M}$ citrate buffer $(\mathrm{pH} 4.5)$ [11].

\section{Experimental Protocol}

The institutional animal ethics committee (Reg. No. 160/1999/CPCESA), Annamalai University, Annamalainagar, India approved the experimental design. A total number of 30 rats were randomized into 5 groups of control and experimental animals and each group consists of six rats. Group I rats were served as untreated control. Group II rats were treated with single intraperitoneal injection of streptozotocin $(50 \mathrm{mg} / \mathrm{kg}$ b.w. ip $)$ dissolved in $0.1 \mathrm{M}$ citrate buffer $(\mathrm{pH} 4.5)$. Group III rats received oral administration of PgEFet (400 mg/kg b.w. po) daily for 45 days by gastric gavage after the diabetic state was assessed. Group IV rats received oral administration of glibenclamide $(600 \mu \mathrm{g} / \mathrm{kg}$ b.w. ip $)$ daily for 45 days by gastric gavage after the diabetic state was assessed. Group $\mathrm{V}$ rats received oral administration of PgEFet (400 mg/kg b.w. po) alone daily for 45 days by gastric gavage.

\section{Biochemical Estimations}

Biochemical estimations were carried out in blood and liver samples of control and experimental rats in each group. Urine sugar was detected by the method of Benedict's test [12]. Blood glucose was estimated by the method of O-toluidine using the modified reagent of Sasaki et al. [13]. The plasma insulin was assayed by ELISA (Enzyme Linked Immumo Sorbant Assay) method using Boehringer Mann- heim kit (Boehringer analyzer Es 300) [14]. Hemoglobin and glycosylated hemoglobin levels were measured by the method of Drabkin and Austin [15] and Sudhakar Nayak and Pattabiraman [16] respectively. The activities of hexokinase, glucose-6-phosphatase, glucose-6-phosphate dehydrogenase (G6PDH) and glycogen phosphorylase were determined in the liver by the methods of Brandstrup et al. [17], Koida and Oda [18], Ellis and Kirkman [19] and Shull et al. [20] respectively. Glycogen content in liver was estimated by the method of Morales et al. [21]. The protein content was estimated by the method of Lowry et al. [22]. Thiobarbituric acid reactive substances (TBARS), the by-product of lipid peroxidation, in plasma and liver were assayed by the methods of Yagi [23] and Ohkawa et al. [24], respectively. Superoxide dismutase (SOD), catalase (CAT) and glutathione peroxidase (GPx) activities were estimated according to the methods of Kakkar et al. [25], Sinha [26] and Rotruck et al. [27] respectively. Reduced glutathione was measured according to the method of Beutler and Kelley [28].

\section{Statistical Analysis}

The data are expressed as mean \pm SD. Statistical comparisons were performed by One-way analysis of variance (ANOVA) followed by Duncan's Multiple Range Test (DMRT). The results were considered statistically significant if the $\mathrm{p}$ value was less than 0.05 .

\section{RESULTS}

Table 1 shows the status of blood glucose, urinary sugar, total hemoglobin, glycosylated hemoglobin and plasma insulin in control and experimental rats in each group. The levels of blood glucose and glycosylated hemoglobin were significantly increased whereas total hemoglobin and plasma insulin levels were significantly decreased in diabetic rats as compared to control rats. However, the above mentioned biochemical parameters were significantly brought back to near normal range in diabetic rats treated with PgEFet and diabetic rats treated with glibenclamide. We also found high levels of urinary sugar in diabetic rats, which was reverted to normal condition in diabetic rats treated with PgEFet and diabetic rats treated with glibenclamide. No statistical significance was observed between control rats and rats treated with PgEFet alone.

Table 2 shows the activities of hexokinase and glucose-6phosphatase in liver of control and experimental rats in each group. Hexokinase activity was significantly decreased, whereas glucose-6-phosphatase activity was increased in the liver of diabetic rats as compared to control rats. However, the activities of hexokinase and glucose-6-phosphatase were returned to near normal range in diabetic rats treated with PgEFet and diabetic rats treated with glibenclamide. Wistar rats treated with PgEFet alone showed no significant difference in hexokinase and glucose-6-phosphatase activities as compared to control rats.

Table 3 shows the activities of glucose-6-phosphate dehydrogenase and glycogen phsophorylase and glycogen content in liver of control and experimental rats in each group. The activities of glucose-6-phosphate dehydrogenase and glycogen content were decreased whereas glycogen phosphorylase activity was increased in the liver of diabetic 
Table 1. Blood Glucose, Urinary Sugar, Plasma Insulin, Total Hemoglobin and Glycosylated Hemoglobin of Control and Experimental Rats in Each Group

\begin{tabular}{|c|c|c|c|c|c|c|}
\hline S. No & Groups & $\begin{array}{c}\text { Fasting Blood } \\
\text { Glucose (mg /dl) }\end{array}$ & Urine Sugar & $\begin{array}{l}\text { Plasma Insulin } \\
(\boldsymbol{\mu} \mathbf{~ U} / \mathbf{m l})\end{array}$ & $\begin{array}{l}\text { Total Hemoglobin } \\
(\mathbf{g} / \mathbf{d l})\end{array}$ & $\begin{array}{l}\text { Glycosylated Hemoglobin } \\
\left(\mathbf{H b} \mathbf{A}_{\mathbf{~}} \%\right)\end{array}$ \\
\hline \hline 1 & Control & $89.77 \pm 7.67^{\mathrm{a}}$ & Nil & $14.29 \pm 1.15^{\mathrm{a}}$ & $15.9 \pm 1.9^{\mathrm{a}}$ & $3.41 \pm 0.22^{\mathrm{a}}$ \\
\hline 2 & Diabetic control & $315.70 \pm 27.67^{\mathrm{b}}$ & +++ & $8.69 \pm 0.59^{\mathrm{b}}$ & $8.96 \pm 0.59^{\mathrm{b}}$ & $7.29 \pm 0.46^{\mathrm{b}}$ \\
\hline 3 & Diabetic control + PgEFet & $102.95 \pm 10.8^{\mathrm{c}}$ & Nil & $12.98 \pm 0.81^{\mathrm{c}}$ & $13.6 \pm 1.3^{\mathrm{c}}$ & $3.78 \pm 0.33^{\mathrm{c}}$ \\
\hline 4 & Diabetic control + glibenclamide & $100.61 \pm 8.9^{\mathrm{c}}$ & Nil & $13.01 \pm 0.83^{\mathrm{c}}$ & $13.3 \pm 1.7^{\mathrm{c}}$ & $3.81 \pm 0.34^{\mathrm{c}}$ \\
\hline 5 & PgEFet alone & $92.62 \pm 6.69^{\mathrm{a}}$ & Nil & $14.09 \pm 1.06^{\mathrm{a}}$ & $15.7 \pm 1.5^{\mathrm{a}}$ & $3.46 \pm 0.25^{\mathrm{a}}$ \\
\hline
\end{tabular}

Values are given as mean \pm S.D ( $=6$ rats). Values that do not share a common superscript letter in the same column differ significantly at $\mathrm{p}<0.05$ (DMRT). (+++) - indicates more than $1 \%$. PgEFet - Punica granatum flower ethanolic extract.

Table 2. Activities of Hexokinase and Glucose-6-Phosphatase in Liver of Control and Experimental Rats in Each Group

\begin{tabular}{|c|c|c|c|}
\hline S. No & Groups & Hexokinase (U*/g of Protein) & Glucose-6-Phosphatase (U**/mg of Protein) \\
\hline 1 & Control & $139.95 \pm 11.44^{\mathrm{a}}$ & $3.14 \pm 0.27^{\mathrm{a}}$ \\
\hline 2 & Diabetic control & $98.07 \pm 6.73^{\mathrm{b}}$ & $5.11 \pm 0.21^{\mathrm{b}}$ \\
\hline 3 & Diabetic control + PgEFet & $123.25 \pm 10.88^{\mathrm{c}}$ & $3.53 \pm 0.28^{\mathrm{c}}$ \\
\hline 4 & Diabetic control + glibenclamide & $125.25 \pm 10.52^{\mathrm{c}}$ & $3.57 \pm 0.31^{\mathrm{c}}$ \\
\hline 5 & Control + PgEFet & $138.25 \pm 11.8^{\mathrm{a}}$ & $3.15 \pm 0.26^{\mathrm{a}}$ \\
\hline
\end{tabular}

Values are given as mean $\pm \mathrm{S} . \mathrm{D}(\mathrm{n}=6$ rats). Values that do not share a common superscript letter differ significantly at $\mathrm{p}<0.05$ (DMRT). PgEFet - Punica granatum flower ethanolic extract. *- Micromoles of glucose phosphorylated/min. **- Micromoles $\mathrm{P}_{\mathrm{i}}$ liberated/min.

Table 3. Activities of Glucose-6-Phosphate Dehydrogenase, Glycogen Phosphorylase and Glycogen Content in Liver of Control and Experimental Rats in Each Group

\begin{tabular}{|c|c|c|c|c|}
\hline S. No & Groups & $\begin{array}{c}\text { Glucose-6-Phosphate Dehydrogenase } \\
(\mathbf{x 1 0} \text { m IU/mg Protein) }\end{array}$ & $\begin{array}{c}\text { Glycogen Phosphorylase } \\
\left(\mathbf{U}^{*} / \mathbf{m g} \text { Protein) }\right.\end{array}$ & $\begin{array}{c}\text { Glycogen (mg Glucose/g } \\
\text { Tissues) }\end{array}$ \\
\hline \hline 1 & Control & $4.16 \pm 0.23^{\mathrm{a}}$ & $2.89 \pm 0.27^{\mathrm{a}}$ & $36.22 \pm 3.19^{\mathrm{a}}$ \\
\hline 2 & Diabetic control & $2.41 \pm 0.26^{\mathrm{b}}$ & $4.45 \pm 0.39^{\mathrm{b}}$ & $21.49 \pm 2.02^{\mathrm{b}}$ \\
\hline 3 & Diabetic control + PgEFet & $3.69 \pm 0.43^{\mathrm{c}}$ & $3.29 \pm 0.33^{\mathrm{c}}$ & $32.14 \pm 2.93^{\mathrm{c}}$ \\
\hline 4 & Diabetic control + glibenclamide & $3.72 \pm 0.33^{\mathrm{c}}$ & $3.23 \pm 0.26^{\mathrm{c}}$ & $31.46 \pm 2.98^{\mathrm{c}}$ \\
\hline 5 & Control + PgEFet & $4.15 \pm 0.29^{\mathrm{a}}$ & $2.92 \pm 0.25^{\mathrm{a}}$ & $35.92 \pm 3.10^{\mathrm{a}}$ \\
\hline
\end{tabular}

Values are given as mean \pm SD ( $n=6$ rats). Values that do not share a common superscript letter differ significantly at $\mathrm{p}<0.05$ (DMRT). PgEFet - Punica granatum flower ethanolic extract. * - Micromoles of Pi liberated/min.

rats as compared to control rats. However, the activities of glucose-6-phosphate dehydrogenase, glycogen phosphorylase and glycogen content were returned to near normal range in diabetic rats treated with PgEFet and diabetic rats treated with glibenclamide. Wistar rats treated with PgEFet alone showed no significant difference in glucose-6phosphate dehydrogenase and glycogen phsophorylase activities and glycogen content as compared to control rats.

Table 4 shows the status of TBARS and antioxidants in plasma and liver of control and experimental rats in each group. The status of TBARS was significantly increased whereas antioxidants were significantly decreased in diabetic rats as compared to control rats. Oral administration of PgEFet to diabetic rats significantly decreased the levels of TBARS and improved the status of antioxidants. The effect of PgEFet was much comparable to that of glibenclamide. No significant difference was observed between control rats and rats treated with PgEFet alone.

\section{DISCUSSION}

Punica granatum flowers exhibited significant antihyperglycemic effect in streptozotocin induced diabetic rats. This was evident by significant decrease in blood glucose level, glycosylated hemoglobin and increase in plasma insulin, total hemoglobin and lowered liver glycogen content in diabetic rats after treatment with PgEFet. An increase in total hemoglobin and decrease in glycosylated hemoglobin in diabetic rats after treatment with PgEFet indicates its ability to prevent the glycosylation process between blood glucose and protein moiety of total hemoglobin during 
Table 4. Levels of TBARS and Antioxidants in Liver and Plasma of Control and Experimental Rats in Each Group

\begin{tabular}{|c|c|c|c|c|c|}
\hline$\frac{\frac{\text { Liver }}{\text { TBARS (mmol/100g tissues) }}}{\text { TBA }}$ & $0.75 \pm 0.05^{\mathrm{a}}$ & $1.89 \pm 0.08^{\mathrm{b}}$ & $0.85 \pm 0.08^{\mathrm{c}}$ & $0.82 \pm 0.07^{\mathrm{c}}$ & $0.73 \pm 0.04^{\mathrm{a}}$ \\
\hline $\begin{array}{l}\text { GSH (mg/ } \\
\text { 100mg tissues) }\end{array}$ & $45.2 \pm 3.7^{\mathrm{a}}$ & $18.6 \pm 4.05^{\mathrm{b}}$ & $39.8 \pm 3.98^{\mathrm{c}}$ & $40.6 \pm 3.6^{\mathrm{c}}$ & $45.6 \pm 3.9^{\mathrm{a}}$ \\
\hline SOD $\left(\mathrm{U}^{* * / m g}\right.$ protein $)$ & $3.15 \pm 0.29^{\mathrm{a}}$ & $1.98 \pm 0.18^{\mathrm{b}}$ & $2.71 \pm 0.25^{\mathrm{c}}$ & $2.69 \pm 0.27^{\mathrm{c}}$ & $3.12 \pm 0.31^{\mathrm{a}}$ \\
\hline CAT $\left(\mathrm{U}^{* * *} / \mathrm{mg}\right.$ protein $)$ & $75.82 \pm 5.24^{\mathrm{a}}$ & $39.5 \pm 3.81^{\mathrm{b}}$ & $69.27 \pm 4.14^{\mathrm{c}}$ & $68.9 \pm 4.91^{\mathrm{c}}$ & $76.2 \pm 5.29^{\mathrm{a}}$ \\
\hline$\frac{\text { Plasma }}{\text { TBARS }(\mathrm{mmol} / \mathrm{ml})}$ & $1.59 \pm 0.13^{\mathrm{a}}$ & $3.11 \pm 0.24^{b}$ & $1.79 \pm 0.15^{\mathrm{c}}$ & $1.83 \pm 0.17^{\mathrm{c}}$ & $1.57 \pm 0.19^{\mathrm{a}}$ \\
\hline GSH (mg/dl) & $26.9 \pm 1.9^{\mathrm{a}}$ & $15.1 \pm 1.4^{\mathrm{b}}$ & $24.17 \pm 2.2^{\mathrm{c}}$ & $23.9 \pm 2.3^{\mathrm{c}}$ & $27.1 \pm 2.4^{\mathrm{a}}$ \\
\hline
\end{tabular}

Values are given as mean \pm SD $(n=6$ rats). Values that are not share a common superscript letter in the same column differ significantly at $\mathrm{p}<0.05$ (DMRT). $*-$ Micrograms of Pi liberated/min. PgEFet - Punica granatum flower ethanolic extract.

hyperglycemic conditions. The antidiabetic potential of Punica granatum flowers are probably due to the presence of one or more bioactive antihyperglycemic principles, such as flavonoids, isoflavones, and their synergistic effects. Increased plasma insulin levels in PgEFet treated diabetic rats suggested that the PgEFet might have stimulated insulin secretion from surviving pancreatic $\beta$-cells.

Liver, the major metabolic organ, has pivotal role in maintaining blood glucose homeostasis. Insulin regulates the metabolism of carbohydrates in the liver. The reduced glycogen content observed in diabetic rats may be associated with increase in glycogen phosphorylase activity. Disturbed activities of carbohydrate metabolizing enzymes in diabetic rats indicate that the carbohydrate metabolic pathways (glycolysis, glycogenolysis, glycogenesis and gluconeogenesis) were severely affected, which was probably due to insulin deficiency. Oral administration of PgEFet brought back the activities of glucose-6-phosphatase, glucose-6phosphate dehydrogenase, hexokinase, glycogen phosphorylase and glycogen content to near normal range in the liver of diabetic rats. Our results demonstrated the ability of PgEFet to correct the carbohydrate metabolic alterations during diabetes mellitus, which confirm the antidiabetic efficacy of Punica granatum flowers.

Measurement of plasma TBARS is considered as the most reliable marker to assess the extent of tissue damage in pathological conditions [29]. Profound studies have shown enhanced oxidative stress in both experimental and human diabetes mellitus [5, 6, 30]. Increased levels of liver TBARS has been documented well in diabetic rats [31, 32]. Our results corroborate these observations. Increased plasma TBARS noticed in diabetic rats could be due to over production and diffusion of lipid peroxidation by products from damaged pancreatic and liver tissues with subsequent leakage in to plasma. Oral administration of PgEFet brought back the levels of plasma and liver TBARS to normal range in diabetic rats, which indicates its free radical scavenging property. The free radical scavenging property of PgEFet indicates that Punica granatum flowers may contain potent antioxidant principles.
Both enzymatic and non-enzymatic antioxidant defense system were impaired in streptozotocin induced diabetic rats $[6,33]$. Lowered activities of enzymatic antioxidants and reduced levels of non-enzymatic antioxidants observed in plasma and liver of streptozotocin induced diabetic rats suggest that these antioxidants are exhausted to combat the deleterious effects of increased oxidative stress. Oral administration of PgEFet to diabetic rats significantly improved the antioxidant defense mechanism, which suggests its role in the protection of vital tissues from oxidative damage during diabetic condition.

The present study thus demonstrated the glucose lowering effect and anti-lipid peroxidative potential of PgEFet in streptozotocin induced diabetic rats. Although the exact mechanism of antidiabetic efficacy of PgEFet is unclear, its anti-lipid peroxidative and modulating effect on the activities of carbohydrate metabolizing enzymes during diabetic condition may play a possible role. Further studies are therefore warranted to isolate and characterize the bioactive antidiabetic and antioxidant principles from Punica granatum flowers.

\section{REFERENCES}

[1] Singh RB, Singh NK, Vajpeyee S, et al. Prevalence and prevention of hypertension, diabetes mellitus and coronary artery disease in India: a scientific statement of the Indian society of hypertension, international college of nutrition and international college of cardiology. In: Current Trends in Hypertension, Diabetes and Coronary Artery Diseases. Singh NK et al. (Eds). BHU press, Varanasi 2008; pp. 186-98.

[2] King H, Aubert RE, Herman WH. Global burden of diabetes, 19952025: prevalence, numerical estimates, and projections. Diabetes Care 1998; 21: 1414-31.

[3] Lenzen S. The mechanisms of alloxan- and streptozotocin-induced diabetes. Diabetologia 2008; 5: 216-26.

[4] Maritim AC, Sanders RA, Watkins JB. Diabetes, oxidative stress and antioxidants. A Review. J Biochem Mol Toxicol 2003; 17: 24 38 .

[5] Kedziora-Kornatowska K, Szewczyk-Golec K, Kozakiewicz M, et al. Melatonin improves oxidative stress parameters measured in the blood of elderly type 2 diabetic patients. J Pineal Res 2009; 46: 333-7. 
[6] Pavana P, Sethupathy S, Manoharan S. Antihyperglycemic and antilipidperoxidative effects of Tephrosia purpurea seed extract in streptozotocin induced diabetic rats. Indian J Clin Biochem 2007; 22: 77-83.

[7] Jurenka JS. Therapeutic applications of pomegranate (Punica granatum L.): a review. Altern Med Rev 2008; 13: 128-44.

[8] Katz SR, Newman RA, Lansky EP. Punica granatum: heuristic treatment for diabetes mellitus. J Med Food 2007; 10: 213-7.

[9] Jafri MA, Aslam M, Javed K, Singh S. Effect of Punica granatum Linn. (flowers) on blood glucose level in normal and alloxaninduced diabetic rats. J Ethnopharmacol 2000; 70: 309-14.

[10] Manoharan S, Ranezab Anishkumar P, Panjamurthy K, Vellaichamy L, Linsa Mary A. Modifying effect of Punica granatum flowers on lipids and lipids-metabolizing enzymes status in streptozotocin induced diabetic rats. World Heart J 2009, (In press).

[11] Chang KJ. Effect of taurine and beta alanine on morphological changes of pancreas in streptozotocin-induced diabetic rats. Adv Exp Med Biol 2000; 483: 571-7.

[12] Varley H. Practical Clinical Biochemistry $4^{\text {th }}$ ed. CBS publishers and distributors. New Delhi 2003; pp. 80-1.

[13] Sasaki T, Matsy S, Sonae A. Effect of acetic acid concentration on the color reaction in the o-toluidine boric acid method for blood glucose estimation. Rinsho Kagaku 1972; 1: 346-53.

[14] Anderson L, Dinesen B, Jorgesen PN, Poulsen F, Roder MF. Enzyme immuno assay for intact human insulin in serum or plasma. Clin Chim Acta 1993; 38: 578-85

[15] Drabkin DL, Austin JM. Spectrophotometric constants for common hemoglobin derivatives in human, dog and rabbit blood. J Biol Chem 1932; 98: 719-33.

[16] Sudhakar Nayak S, Pattabiraman TN. A new colorimetric method forms the estimation of glycosylated hemoglobin. Clin Chim Acta 1981; 109: 267-74.

[17] Brandstrup N, Kirk JE, Bruni C. Determination of hexokinase in tissues. J Gerontol 1957; 12: 166-71.

[18] Koida H, Oda T. Pathological occurrence of glucose-6-phosphatase in liver disease. Clin Chim Acta 1959; 4: 554-61.

[19] Ellis HA, Kirkman HN. A colorimetric method for assay of erythrocyte glucose-6-phosphate dehydrogenase. Proc Soc Exp Biol Med 1961; 106: 607-9.
[20] Shull KH, Ashmore J, Mayer J. Hexokinase, glucose-6phosphatase and phosphorylase levels in hereditarily obese hyperglycemic mice. Arch Biochem Biophys 1956; 62: 210-6.

[21] Morales MA, Jabbagy AJ, Terenzi HF. Mutations affecting accumulation of glycogen. Neurospora News Lett 1973; 20: 24-5.

[22] Lowry OH, Roeshorough NJ, Farr AL, Randall RJ. Protein measurement with Folin - phenol reagent. J Biol Chem 1951; 193: 26575 .

[23] Yagi K. Lipidperoxides and human disease. Chem Phys Lipids 1978; 45: 337-51.

[24] Ohkawa H, Ohishi N, Yagi K. Assay for lipid peroxidation in animal tissues by thiobarbituric acid reaction. Anal Biochem 1979; 95: 351-8.

[25] Kakkar P, Das B, Viswanathan P. A modified spectrophotometric assay of superoxide dismutase. Indian J Biochem Biophys 1984; 21: 130-2.

[26] Sinha KA. Colorimetric assay of catalase. Anal Biochem1972; 47: 389-94.

[27] Rotruck JT, Pope AL, Ganther HE, Swanson AB. Selenium biochemical roles as a component of glutathione peroxidase. Science 1984; 179: 588-90

[28] Beutler E, Kelley BM. The effect of sodium nitrate on RBC glutathione. Experientia 1963; 19: 96-7.

[29] Gutteridge JMC. Lipid peroxidation and antioxidant as biomarkers of tissue damage. Clin Chem 1995; 14: 1819-28.

[30] Rajani Kanth V, Uma Maheswara Reddy P, Raju TN. Attenuation of streptozotocin-induced oxidative stress in hepatic and intestinal tissues of Wistar rat by methanolic-garlic extract. Acta Diabetol 2008; 45: 243-51.

[31] Punitha R, Manoharan S. Antihyperglycemic and antilipidperoxidative effects of Pongamia pinnata (Linn.) Pierre flowers in alloxan induced diabetic rats. J Ethnopharmacol 2006; 105: 39-46.

[32] Manoharan S, Silvan S, Vasudevan K, Balakrishnan S. Antihyperglycemic and antilipidperoxidative effects of Piper longum (Linn.) dried fruits in alloxan induced diabetic rats. J Biol Sci 2007; 6: 161-8.

[33] Manoharan S, Gitanjali M, Linsa Mary A, Chellammal A, Vasudevan K, Balakrishnan S, Vellaichamy L. Antihyperglycemic and antilipidperoxdative potential of Ceiba pentandra in streptozotocin-induced diabetic rats. Cell Tissue Res 2009; 9: 1731-6. 